\title{
APPROVAL VISITS: GUIDELINES ON GRITERIA AND FACILITIES FOR TRAINING
}

\section{Introduction}

The Court of Electors has recently reviewed experience of visiting hospitals that are seeking approval of their training schemes for the Membership examination. Some ideas have crystallized about the features that are considered desirable and that should therefore be looked for. The scheme described below is an ideal one and unlikely to be fully realized in many centres at present; but it may be of interest to colleagues whose hospitals are being visited to know the sorts of things the visiting panel will be bearing in mind. These criteria are a modification of draft guidelines developed by Dr Marshall Annear.

\section{Duration of General Professional Training in Psychiatry}

The necessary period of general training in psychiatry before a candidate can sit the examination for the Membership of the Royal College of Psychiatrists is normally three years. During this time the candidate will have been expected to have undergone and actively participated in a comprehensive course of training closely linked to his service commitments. The basis of this training will be in general psychiatry, with additional training in some specialties as outlined below.

\section{Need for a Comprehensive Training in Psychiatry}

The hospital or group of hospitals seeking full approval should be able to provide comprehensive diagnostic and therapeutic facilities relating to the whole field of psychiatry. (In-patient, Out-patient and Community Care, with some specialist experience.)

\section{Adequate Establishments to Provide for Education and Training Needs}

There should be adequate consultant establishment, nursing staff and support staff to fulfil the medical objectives of the institution as well as to provide for education and training needs. In addition, the work load of the Clinical Tutor and Organizer should have been adjusted where necessary to enable tutorial duties to be performed effectively.

\section{Importance of Consultant Staff Participating in a Teaching Role}

Consultant staff who have doctors in training working under their direction should regard actively teaching them to be an essential part of their contribution within the context of postgraduate activities (especially when the trainee doctor functions in an 'apprentice-like' capacity).

\section{Rotation of Doctors-in-Training between Firms and Clinic Sectors}

Rotation of doctors in training between firms is regarded as highly necessary, if not essential. The duration of rotation should be such that it does not conflict with service requirements, nor should it be so long that the trainee would be failing to extend his experience. The period suggested is 9 or 12 months initially in general poychiatry. Considerably shorter periods might be expected during rotation through specialty posts. It is appreciated that the emphasis must be on flexibility.

\section{Experience of Comprehensive Diagnostic Facilities}

Training and experience in relation to various diagnostic departments is important. These should include clinical psychology and some neuropathology, for example electroencephalography.

\section{Experience in the Various Specialties within the Field of Psychiatry}

Doctors in training should gain both hospital and community experience in various specialties within the field of psychiatry. Among these are included:

(i) child and adolescent psychiatry;

(ii) psychogeriatrics;

(iii) mental handicap;

(iv) psychotherapy, including behaviour therapy;

(v) forensic psychiatry;

(vi) dependence (on alcohol and other drugs);

(vii) management of long-stay patients;

(viii) medical administration.

It is unlikely that experience in all of these would be possible during a whole-time rotation because of the almost certain conflict with service needs, but some arrangements should be made for trainees to undergo secondment on a once- or twice-weekly basis for appropriate periods, where whole time experience is not possible.

\section{Continuous Assessment of the Doctor in Training}

Continuous assessment of the doctor in training by consultants and Tutor through enquiring into, and help with, areas of weakness is necessary and should eventually benefit both the trainee and the service.

\section{Provision of a Comprehensive Course of Instruction}

A comprehensive and systematized course of instruction on all necessary subjects is essential through 
lectures, tutorials and seminars, to provide knowlodge, arouse interest, encourage incentive, give breadth of outlook, and generally provide for the requirements for the examinations for the M.R.C.Psych. These formal courses will generally be best mounted on an Area or Regional basis, rather than a hospital one, except where a hospital is very large with many trainees.

\section{I1. Active Participation in Postgraduate Activities}

The doctor in training as part of his experience must be encouraged to participate actively in educational endeavours. This should include regular clinical conferences at which the trainee would present patients. He should also be encouraged to participate in the selection of material for Journal Club purposes, and would be expected to attend Journal Club meetings.

\section{Guidance in Research and Teaching Methods}

Those in training should be helped with simple clinically orientated research procedures, and with guidance in giving lectures and teaching.

\section{Information for Doctors in Training}

All trainees should be provided with appropriate information about the hospital and available postgraduate activities, and given details about examinations for the M.R.C.Psych. as well as the College Handbook for Inceptors and Trainees.
14. Library and Study Facilities

The provision of a good standard of library, with an adequate supply of journals and supporting facilities for study, is essential.

\section{Accommodation for Teaching, Administrative Facilities and Audiovisual Educational Aids}

A seminar/lecture room as a focus for postgraduate activities is necessary, as also is office accommodation for the Clinical Tutor and postgraduate secretary. In addition, there should be adequate provision of audio and visual teaching aids.

\section{Residential Quarters of Doctors in Training}

Satisfactory residential quarters properly maintained should be available for doctors in training, together with adequate study facilities, such as desk, bookcase and desk lamp.

\section{Objectives in Postgraduate Education}

Medical educational and training objectives of the doctor in training should be directed toward achieving the highest possible standards of psychiatric practice in the fullest meaning of the term. The needs of patients in their psychosocial and medical context should be regarded as paramount, and due importance should be attached to the preventive role in medical and psychiatric practice.

\section{COLLEGE ANNOUNGEMENTS}

\section{College Meetings 1979}

Annual and Quarterly Meetings of the College will be on the following dates in 1979. Please note that the date of the Annual Meeting given in the list published in the November 1977 Bulletin (p 10) has been changed.

$\begin{array}{ll}6 \text { and } 7 \text { February } & \text { London } \\ 1 \text { and } 2 \text { May } & \text { Sheffield } \\ 10-12 \text { July } & \text { Exeter (Annual Meeting) } \\ 15 \text { and } 16 \text { November } & \text { London }\end{array}$

\section{Dr Peter Scott Memorial Fund}

The Dr Peter Scott Memorial Fund Appeal Committee would like to thank donors to the Fund, which has now reached $£ 4,000$ approximately. Those who still wish to contribute should send their donations to: The Secretary, Dr Peter Scott Memorial Fund, The Royal College of Psychiatrists, 17 Belgrave Square, London SWIX 8PG. Cheques should be made payable to 'The Royal College of Psychiatrists (Peter Scott Memorial Fund)'. 